\title{
A atualização da experiência humana: o poema em questão
}

Daiane Neumann"

Aroldo Garcia dos Anjos**

\section{Resumo}

O presente trabalho tem por objetivo discutir a noção de enunciação, de Émile Benveniste, como atualização da experiência humana. Para tanto, serão discutidas as noções de experiência e de linguagem, a partir de escritos de Giorgio Agamben, Walter Benjamin e Émile Benveniste. Em um primeiro momento, será considerada a leitura de Agamben das obras de Benjamin e de Benveniste, na qual o autor propõe a experiência da linguagem como origem da história. Posteriormente, será observado como Benveniste constrói sua concepção de linguagem como fundante da experiência, para, por fim, pensar sobre a linguagem e o poema, considerando as reflexões de Henri Meschonnic.

Palauras-chave: Experiência poética. Linguagem. Experiência humana.
Raum

Noch ist Raum

für ein Gedicht

Noch ist das Gedicht ein Raum

Wo man atmen kann.

Rose Ausländer ${ }^{1}$

\section{Introdução}

No metapoema Raum, de 1976, mais que transmissão de uma informação ou expressão de um sentimento, a experiência da linguagem poética é alçada ao nível de um elemento vital essencial: a respiração. A linguagem serve, pois,

\footnotetext{
Professora do curso de Letras e do Programa de Pós-Graduação em Letras da Universidade Federal de Pelotas. E-mail: daiane_neumann@hotmail.com

** Mestrando no Programa de Pós-Graduação da Universidade Federal de Pelotas. E-mail: aroldodosanjos@ gmail.com
}

Data de submissão: 11 dez. 2019 - Data de aceite: 05 fev. 2020 http://dx.doi.org/10.5335/rdes.v16i1.10383 
para viver - como nos ensinou Émile Benveniste. A despeito da incompletude original da linguagem, proposta por Agamben (1979), em um misto de fantasia e esperança, recorre-se ao poema como espaço de refúgio, de recomposição de si. Rememora-se, aqui, a discussão da possibilidade de se fazer poesia após Auschwitz, o paradoxo de conviver com sua impossibilidade. Propõe-se, no entanto, a poesia como espaço da liberdade, da reconstrução: a palavra criadora.

Tendo em vista o poder criativo da palavra, sua condição de constituidora, o presente trabalho tem por objetivo discutir a noção de enunciação, de Émile Benveniste, como atualização fundamental da experiência humana, a fim de pensar sobre a experiência e o poema. Para tanto, serão exploradas as noções de experiência e de linguagem, a partir de escritos de Giorgio Agamben, Walter Benjamin e Émile Benveniste - em seus resgates da experiência subjetiva, enquanto críticos da modernidade, para, por fim, teorizar sobre a experiência do poema, apoiando-se em Henri Meschonnic.

Em um primeiro momento, será considerada a leitura que Agamben faz das obras de Benjamin e de Benveniste, na qual o autor critica as bases da ciência iluminista (Aufklärung) e propõe a experiência da linguagem como origem da história. Posteriormente, será observado como Benveniste constrói sua concepção de linguagem como fundante da expe- riência. Por fim, pretendemos discutir como o poema se torna o locus, por excelência, da atualização dessa experiência e, portanto, da criação.

\section{A expropriação da experiência}

Em Infância e história: destruição da experiência e origem da história, de 1979, o filósofo Giorgio Agamben discute o lugar ao qual foi relegada a experiência humana na tradição filosófica iluminista, assim como a concepção de linguagem que lhe subjaz. Interessa-lhe ir além da dicotomia sujeito-objeto, problematizando a pretensão de verdade oriunda do conhecimento matematizável e da separação entre experiência e conhecimento. Agamben advoga, assim, contra a concepção de uma substância pré-subjetiva ou um sujeito pré-linguístico. Para tanto, apoia-se em Walter Benjamin, em sua crítica à expropriação da experiência humana, e em Émile Benveniste, em sua consideração da linguagem como constituidora da história.

Em um primeiro momento, Agamben evoca a constatação da pauperização do intercâmbio de experiências, diagnosticada por Walter Benjamin em Experiência e pobreza. Em seus escritos de 1933, Benjamin relata o retorno dos soldados, após a experiência nos campos de batalha, emudecidos. $\mathrm{O}$ autor aponta, também, para a destruição da experiên- 
cia no dia a dia aparentemente pacífico das cidades grandes contemporâneas, na perda da experiência comunicável, na recusa à fruição, na autoridade da ciência moderna.

De acordo com a leitura de Benjamin, em Sobre alguns temas em Baudelaire (1939), na modernidade, o homem não tem mais tempo de incorporar os estímulos exteriores, que, dado seu grau excessivo, tornam-se uma experiência inóspita, calcada no choque: das Schockerlebnis. No lugar da experiência significativa e coletiva (Erfahrung), impõe-se a vivência (Erlebnis) assimilada às pressas (BENJAMIN, 1989, p. 109-110).

A Benjamin interessa o que é da ordem do artesanal e que possui ainda alguma aura. Não é à toa que, em $O$ narrador (1936), ao discorrer acerca da oralidade, Benjamin faz referência ao que é manual, ao tecer de redes, ao trabalho com a argila, em suma, à figura do artesão que trabalha "a matéria-prima da experiência” (BENJAMIN, 1996, p. 221). Benjamin opõe a arte de narrar, que integra o acontecimento à vida do narrador, à difusão da informação, simples tentativa de transmissão de acontecimentos, com caráter de verdade.

Essas considerações possuem como pano de fundo uma discussão mais antiga da obra de Benjamin, a saber, a crítica feita pelo autor à instrumentalidade da linguagem, no escrito Sobre a linguagem em geral e sobre a linguagem do homem, de 1916:

A linguagem comunica a essência linguística das coisas. Mas a manifestação mais clara dessa essência é a própria linguagem. A resposta à pergunta "O que comunica a linguagem?" deve ser: "Toda linguagem comunica-se a si mesma" (BENJAMIN, 2011, p. 53).

Para Benjamin, a linguagem constrói realidades, ela não é meio para chegar a uma verdade. Ela é Medium (meio enquanto matéria, ambiente e modo), não Mittel (meio para determinado fim). Daí a imediatidade, die Unmittelbarkeit: a não-instrumentalidade com vistas a um fim exterior (BENJAMIN, 2011, p. 53-54). O homem está, assim, na linguagem. Sua essência é linguística. $\mathrm{O}$ homem significa o mundo ao seu derredor, o homem nomeia as coisas.

Com base na crítica de Benjamin, Agamben afirma que

[...] a ciência moderna nasce de uma desconfiança sem precedentes em relação à experiência como era tradicionalmente entendida (2008, p. 25).

Ao acaso das experiências espontâneas, opõe-se o método. Separa-se, radicalmente, a experiência da ciência. A discussão, da antiguidade, entre o inteligível e o sensível é substituída, na ciência moderna, pelo sujeito transcendental, da consciência, que carrega em si a palavra de autoridade. A fantasia, enquanto meio para chegar ao conhe- 
cimento, é expropriada. Em seu lugar, erige-se o ego cogito.

Discutindo o conceito de experiência muda, de Edmund Husserl, Agamben se pergunta se existiria uma in-fância da experiência. Seria possível pensar numa experiência muda pré-subjetiva? Haveria uma experiência pura antes da linguagem? A partir do questionamento desse espaço de mudez, Agamben tece sua defesa de experiência na linguagem.

Agamben argumenta que o sujeito kantiano foi pensado nos moldes matemáticos, não na linguagem. Tomava-se o sujeito como o centro do seu dizer, e a linguagem, ainda, como um instrumento. A orientação do problema do conhecimento pelo modelo da matemática, tanto em Husserl como em Immanuel Kant, impediu de

[...] perceber a situação original da subjetividade transcendental na linguagem e, portanto, de traçar com clareza os limites que separam transcendental e linguístico (2008, p. 54).

Dessa forma, para Benjamin, em Sobre o programa da filosofia por vir, é face à relação entre conhecimento e linguagem que se empreenderá uma grande transformação e correção em um conceito unilateralmente orientado ao matemático-mecânico, presente na filosofia kantiana. Para o filósofo alemão, Kant teria esquecido, devido à crença de que o conhecimento filosófico é absolutamente apriorístico e seguro, que todo e qualquer conhecimento filosófico possui sua única expressão na linguagem, e não em fórmulas e números.

Agamben apoia-se, então, na crítica de Georg von Hamann a Kant, segundo a qual uma razão pura não pode ser afirmada independentemente da linguagem, uma vez que não há pensamento sem linguagem. Tal crítica já havia sido explorada por Benjamin, em Sobre a linguagem em geral e sobre a linguagem do homem, para propor a experiência e a linguagem como intimamente ligadas. Em sintonia com Benjamin e Hamann, Agamben investiga, assim, as condições preliminares da teoria do conhecimento em seus vínculos com a linguagem. Para tanto, busca a reflexão sobre o papel fundador da linguagem em Ferdinand de Saussure e em Émile Benveniste (2008, p. 56).

\section{A experiência da linguagem como origem da história}

Agamben considera A natureza dos pronomes (1956) e Da subjetividade na linguagem (1958) como estudos fundamentais para consideração do sujeito constituído na e pela linguagem. Ao invés de um "eu" matematizável, em Benveniste encontramos um "eu" linguístico. A subjetividade, a partir de Benveniste, é vista como "a capacidade do locutor pôr-se como um ego" (AGAMBEN, 2008, 
p. 56), criando de modo singular noções de tempo, espaço e pessoa em referência à própria instância enunciativa. Pelas palavras de Benveniste, a realidade à qual o pronome "eu" remete é uma realidade de discurso.

Nos pronomes, o autor reconhece uma classe de palavras que não se deixa enquadrar na definição dos demais signos da língua. A linguagem estaria organizada de modo a permitir a apropriação da língua por parte do locutor, ao designar-se por "eu". Para Benveniste, assim como para Ferdinand de Saussure ${ }^{2}$, não há possibilidade de pensamento sem a língua, uma vez que "o pensamento não pode ser captado a não ser formado e atualizado na língua" (BENVENISTE, 2005, p. 70). Sendo assim, a linguagem não simplesmente espelha algo pensado a priori, ela é constituidora do pensamento. O sujeito, por conseguinte, está sempre diante de uma realidade de discurso, seja porque é constituído por ela, seja porque a constitui.

Essa consideração permite que Agamben perceba que a problemática do $\mathrm{Au}$ fklärung reside, em Kant, na troca de transcendental por linguístico:

[...] o sujeito transcendental não é outro senão o "locutor", e o pensamento moderno erigiu-se sobre esta assunção não declarada do sujeito da linguagem como fundamento da experiência e do conhecimento (AGAMBEN, 2008, p. 57).
Contrapondo-se a Kant e a Husserl, Agamben afirma que a experiência é já sempre "palavra", o que implica a consideração de que não há sujeito a priori, uma vez que este é constituído na linguagem e pela linguagem. À pergunta sobre a existência de algo como a in-fância do homem, ou seja, se há homem antes da linguagem, Agamben responde que é possível encontrar essa infância com o inconsciente freudiano, mas que ele é, assim como o demonstraram Benveniste e Lacan, um $E s$, que não possui outra realidade que não seja de linguagem.

A ideia de uma infância como uma "substância psíquica" pré-subjetiva revela-se então um mito, como aquela de um sujeito pré-linguístico, e infância e linguagem parecem assim remeter uma à outra em um círculo no qual a infância é a origem da linguagem e a linguagem a origem da infância (AGAMBEN, 2008, p. 59).

Para Agamben, a linguagem não é totalidade, pois o humano está sempre implicado. Ela é historicizante. Ela contém em sua origem o não-dito, a infância inapreensível está ali: "O inefável é, na realidade, infância” (AGAMBEN, 2008, p. 63). Segundo Agamben, é a infância que instaura na linguagem a cisão entre língua e discurso, é o hiato entre semiótico e semântico, como concebeu Benveniste:

[...] a natureza do homem é cindida de modo original, porque a infância nela introduz a descontinuidade e a diferença entre língua e discurso (AGAMBEN, 2008, p. 64). 
Assim como para Benjamin, a história é, para Agamben, também, intervalo e descontinuidade, não progresso e linearidade. Experienciar é "reentrar na infância como pátria transcendental da história" (AGAMBEN, 2008, p. 65).

Agamben relaciona sua teoria da infância com as categorias da ciência da linguagem e a toma, assim, como um "desenvolvimento coerente" constituído a partir da distinção entre semiótico e semântico. A expropriação da infância, em Agamben, é a apropriação da linguagem, para Benveniste.

Segundo a leitura de Agamben, o sujeito torna-se sujeito ao entrar na linguagem. É na enunciação, na e pela linguagem, que o homem entra na história. Para Benveniste, não há humano fora da linguagem, pois ela está na natureza do homem, que não a criou. $\mathrm{O}$ humano é história, é essa passagem da língua ao discurso, é devir (AGAMBEN, 2008, p. 67-68).

Agamben afirma que, após Aristóteles, a lógica e a filosofia não mais distinguiram língua de fala, pois tomaram esta como simples uso daquela. A língua como lugar da ciência, domínio do logos, expropriação da experiência. Agamben considera, no entanto, que a distinção entre semiótico e semântico, de Benveniste, permite o questionamento do logocentrismo.
Somente a linguagem humana - na medida em que pertence contemporaneamente ao endossomático e ao exossomático - acrescenta à significação semiótica um sentido outro e transforma o mundo fechado do signo no mundo aberto da expressão semântica (AGAMBEN, 2008, p. 75).

Agamben acredita, assim, que a linguagem se encontra não em uma oposição entre natureza e cultura, mas cindida em uma duplicidade que produz um sistema novo. $\mathrm{O}$ autor crê, entretanto, que há algo que media e possibilita a ressonância entre o sistema endossomático e o exossomático: a infância do homem. Agamben busca a situação limite entre semiótico e semântico - o hiato, pelas palavras de Benveniste.

\section{Enunciação e atualização da experiência}

No texto Da subjetividade na linguagem, Benveniste enfatiza que a palavra é a atualização da linguagem, cuja condição é a intersubjetividade. Essa ideia, introduzida pelo autor em trabalhos anteriores ${ }^{3}$, vai ao encontro da concepção dos domínios semiótico e semântico, os quais Benveniste desenvolve em profundidade nos textos $A$ forma e o sentido na linguagem (1966) e Semiologia da língua (1969), até culminar na noção de enunciação, de modo mais explícito em O aparelho formal da enunciação (1970): 
Tentaremos esboçar, no interior da língua, os caracteres formais da enunciação a partir da manifestação individual que ela atualiza (BENVENISTE, 2006, p. 83).

Benveniste propõe que a enunciação seja o espaço da singularidade, das designações sempre novas. $\mathrm{O}$ ato de apropriação da língua pelo locutor o introduz em sua própria fala e o faz passar a atribuir referência. Segundo Benveniste (2006, p. 84), cada instância de discurso constitui "um centro de referência interno", criando, a partir de "eu", as noções de tempo, de espaço e os próprios atores - entidades linguísticas nascidas na enunciação. Em sua tríade pessoa-tempo-espaço, a enunciação, enquanto ato de apropriação individual da língua, re-produz ${ }^{4}$ o mundo por meio do discurso, sempre de uma maneira nova.

Voltando, oportunamente, ao texto A linguagem e a experiência humana (1965), podemos ver que Benveniste retomava ali a discussão sobre os pronomes enquanto formas que recebem sua realidade e sua substância somente no discurso, possuindo a língua formas que permitem a atualização da experiência e a própria existência do discurso: "Esta é a atualização de uma experiência essencial, que não se concebe possa faltar a uma língua” (BENVENISTE, 2006, p. 69).

Benveniste avança na discussão ao demonstrar que os dêiticos organizam o espaço e o tempo tomando o "eu" como referência, dando especial atenção às formas que exprimem o tempo, por considerá-las as mais ricas no que toca à revelação da experiência subjetiva na língua. É a radicalidade da noção de enunciação que permite Benveniste considerar o tempo linguístico como aquilo que significa os demais tempos, físico e crônico. O presente da instância de fala constrói as ideias de passado (temporalidade retrospectiva) e de futuro (temporalidade prospectiva): “este presente é reinventado a cada vez que um homem fala porque é, literalmente, um momento novo, ainda não vivido" (BENVENISTE, 2006, p. 75).

Nascido na enunciação, o presente axial do discurso é a referência a partir da qual a língua ordena o tempo: "Do tempo linguístico indicamos a sua emergência no seio da instância de discurso que o contém em potência e que o atualiza" (BENVENISTE, 2006, p. 77). Essa interpretação será reforçada em $O$ aparelho formal da enunciação, de 1970:

O presente formal não faz senão explicitar o presente inerente à enunciação, que se renova a cada produção de discurso, e a partir deste presente contínuo, coextensivo à nossa própria presença, imprime na consciência o sentimento de uma continuidade que denominamos 'tempo'; continuidade e temporalidade que se engendram no presente incessante da enunciação, que é o presente do próprio ser e que se delimita, por referência interna, entre o que vai se tornar e o que já não o é mais (BENVENISTE, 2006, p. 85-86). 
Nesse trajeto esboçado, percebe-se que Benveniste, ao refletir acerca da atualização, discute não somente um aspecto linguístico, mas também um processo de construção da experiência humana. A atualização do signo em uma instância de discurso é, assim, parte essencial da enunciação. É sob a condição da intersubjetividade, em um aqui e agora sui referenciais, que a língua-discurso constrói os sentidos particulares e possibilita que o homem se singularize. $\mathrm{O}$ sujeito da linguagem é posto em ação pelo homem. Este, por sua vez, ganha significação pelo sujeito da linguagem.

A linguagem se torna, portanto, o locus da experiência humana. É por meio dela que se dá, conforme já aqui teorizado, o nascimento da história, a produção do conhecimento. Esse poder fundador da linguagem, no entanto, encontra espaço para alcançar toda a tua potência no poema.

\section{A experiência e o poema}

No poema ${ }^{5}$, a propriedade da linguagem de constituir o locus da experiência, da construção da história e da produção do conhecimento ficam mais evidentes do que em qualquer outro lugar. Deve-se a essa constatação o fato de que a experiência poética possa ser alçada ao nível de um elemento vital e essencial: a respiração. Deve-se à experiência com o poema também a possibilidade de ler- mos em Benveniste a sua famosa frase "A linguagem serve para viver" em toda a sua potência.

Se encontra, assim, no poema, um espaço de refúgio, de recomposição de si, justamente devido àquilo que pode a linguagem nessa experiência. Nela, encontra-se novamente a fantasia, que também figura como um meio de busca pelo conhecimento, do qual nos desapropriou a ciência moderna, em nome do ego cogito.

Conforme Dessons ${ }^{6}$, no que se convencionou chamar de "discurso ordinário", os marcadores de enunciação são compatíveis com uma tipologia compartilhada por todos os locutores de um grupo linguístico. Assim, tais marcadores asseguram um funcionamento da linguagem que leva a se relacionar um enunciado a um sujeito particular. $\mathrm{Na}$ linguagem poética, se inventam esses marcadores subjetivos. O conjunto do texto, portanto, se torna um marcador de subjetivação. Se está não mais em um terreno familiar, mas em uma terrae incognitae (terras desconhecidas). Os indicadores são embaralhados e é o conjunto do discurso que se torna um marcador potencial de subjetividade. Daí advém sua propriedade de se constituir como o lugar em que se pode respirar, como o lugar em que se pode tentar nomear aquilo que não pode ser nomeado, alcançar aquilo que nos escapa. 
Essa propriedade é denominada por Meschonnic (2006), recuperando o termo de Benveniste (2006), significância. Quando o sentido escapa ou se perde, estamos diante da significância. De acordo com o poeta, linguista e tradutor, o que nos escapa é uma força, que seria o sujeito, uma historicidade. A força se constitui, portanto, como a passagem de um sujeito a um outro sujeito, o que os constrói. O poema é, assim, a alegoria do sujeito.

Assim, no poema, se pode entrar em uma subjetividade extrema a fim de que se alcance o sujeito em sua plenitude. O poema, de acordo com Meschonnic (2006), se situa no conflito entre a experiência e a cultura, entre a rima e a vida. Por isso, figuraria mais como uma contracultura na cultura, quando esta última é concebida como o lugar do que é estabelecido. Dessa forma, o poema acaba por atravessar as fronteiras e as línguas. Deve-se à tal subversão a impressão de que se cria outra língua, o que leva Benveniste (2011), ao estudar a obra de Baudelaire, a mencionar a expressão "língua de Baudelaire".

Ao considerar as propriedades da linguagem poética aqui destacadas, Meschonnic (2006) afirma que o poema seria um atraso e um desvio, por isso, seria o único modo de linguagem capaz de dizer o que não pode ser dito, na medida em que incorpora o silêncio. $\mathrm{O}$ teórico ainda cita Milosz ${ }^{7}$, para quem
[...] quando a realidade ultrapassa todos os meios de nomeá-la, ela só pode ser abordada de uma maneira indireta, através de reflexões que ela projeta na subjetividade de alguém.

O poema, para Meschonnic (2006), é então uma forma de vida que faz de tudo linguagem. Assim o poema, uma forma de vida, não cessa de nos trabalhar, de ser o sonho do qual somos o sono, pois figura como uma escuta, um despertar que nos atravessa. O poema organiza na linguagem tudo o que foi considerado algo que escapava à linguagem: a vida, o movimento do que nenhuma palavra cessa de poder dizer.

A escritura se torna, portanto, uma forma de vida, movimento de uma fala, invenção de um sujeito pela sua linguagem e de sua linguagem por um sujeito inseparavelmente. A escritura é a invenção de sua própria historicidade. A partir de tal concepção de linguagem, não há mais temas ou sentimentos de um lado e formas de outro, mas uma subjetivização e uma historicização radical de toda a linguagem. Deriva dessa concepção de linguagem, ainda, a possibilidade de transformação da relação com os outros, consigo mesmo e com o mundo, pois a escritura e a vida se transformam uma pela outra, "la rime et la vie se transformant l'une par l'autre" (MESCHONNIC, 2006, p. 127).

No entanto, o poema nos intriga, na medida em que, conforme pontua Pau- 
$\operatorname{lhan}^{8}$, a poesia não escapa à condição da linguagem comum, o que acontece é exatamente o contrário, pois o mistério que encanta todos os olhares fascinados está na "linguagem mais elementar". Conforme o destaca Meschonnic (2006), o poema toma a linguagem ordinária e mostra que tudo na linguagem é ordinário. Assim, pelo poema, não haveria mais linguagem ordinária.

Compreender o poema seria colocar-se em um lugar de escuta, já que as transformações propostas por esse discurso se dariam em todos os níveis da linguagem, acentual, prosódico, morfológico, sintático, lexical. A teoria da linguagem deveria, portanto, colocar-se como a escuta dessa escuta. A teoria da linguagem seria uma escuta das transformações que acontecem na linguagem.

Contudo, se o poema é o lugar, por excelência, das transformações que ocorrem na linguagem, ele precederia a teoria, não somente a teoria da linguagem, mas também do conhecimento. Os desafios e a riqueza oferecidos pelos poemas não concernem somente ao estudioso da linguagem, na medida em que, conforme D’Alembert (1822), o encontro necessário e hábil de alguns termos conhecidos, utilizados pelos escritores, introduzem energicamente novas ideias.

Dessa forma, se a linguagem é concebida como o lugar da individuação, a "bela linguagem" se torna o que encontramos no ordinário mesmo. Não pode ser de outra maneira, se considerarmos que a linguagem passa por um sujeito que a transforma. Assim, a beleza, segundo Meschonnic (2006), não é mais formal, nem mesmo semântica, mas uma crítica a essa dualidade. A beleza não é mais estética, mas ética. Ela não diz mais respeito à forma ou ao sentido, mas à individuação. O belo na linguagem passa por uma aventura da historicidade.

Se tomarmos a reflexão sobre linguagem proposta por Benveniste e Meschonnic, não se pode dissociar o que tradicionalmente se dissociou, a semântica e a pragmática. Logo, ao considerar que a linguagem, por sua característica de ser o locus da individuação e da experiência humana, é um objeto ético, não se pode dela dissociar a propriedade de ser também, ao mesmo tempo, um objeto político, na medida em que a linguagem, da mesma forma, é sempre também uma ação sobre o mundo.

Portanto, o poema figura como um ato ético e político. A poética se torna, assim, uma poética da sociedade, na medida em que a sociedade e o pensamento da sociedade se mostram na sua concepção de linguagem e naquilo que a sociedade faz de sua linguagem (MESCHONNIC, 2006).

\section{Palavras finais}

No processo de compreensão da destruição da experiência e da origem da história, Giorgio Agamben promove uma 
articulação entre as ideias de Walter Benjamin e de Émile Benveniste - dentre as quais, as noções de linguagem e de tempo podem ser sublinhadas.

Benjamin, ao opor-se ao lógos, intuiu que a essência do homem é linguística. Benveniste acreditou que a linguagem está na natureza do homem, que não a inventou. Ambos autores pensam o tempo de modo qualitativo, não simplesmente cronológico. Benjamin considera o tempo presente como repleto de história, o Jetztzeit ${ }^{9}$, uma agoridade, um presente no qual reverbera a história. Benveniste considera o tempo linguístico como constituidor dos demais tempos. É o tempo da enunciação, da atualização da experiência. Em ambos, o que articula os tempos é o homem, nascido na linguagem. Aí está o humano - esse hiato entre semiótico e semântico.

Para Agamben, a infância do homem, origem da experiência e da história, situa-se articulada sobre a dupla herança de natureza (endossomática) e cultura (exossomática). Ela coloca os dois sistemas em ressonância e permite que se comuniquem. Aí está a passagem do semiótico ao semântico, que Benveniste buscava ao estudar a obra de Saussure.

Fazendo uso da discussão levada a cabo por Benveniste desde A forma e o sentido na linguagem, Agamben defende a tese de que, também, a poesia vive na tensão e no contraste entre o som e o sentido, entre a série semiótica e a série semântica (AGAMBEN, 2002, p. 142). À pergunta sobre a possibilidade de ainda hoje fazer experiência, Agamben parece responder que a linguagem humana, através da arte, da fantasia, poderia tentar tocar algo da infância, uma vez que ela é um espaço privilegiado de flerte com o indizível, ela é potência. A linguagem na qual e através da qual se respira, como no poema de Rose Ausländer, é a linguagem como fluxo e devir, não ritmo pré-determinado e instrumento. É a história como descontinuidade. O poder criativo não está apenas na poesia, embora esta seja o espaço de uma experimentação mais evidente. Ele está na mátria ${ }^{10}$, na linguagem como experiência.

Embora o poema seja o lugar de nomear aquilo que não pode ser nomeado, de dizer o que não pode ser dito, de tocar o que nos escapa, é preciso relembrar que ele está na linguagem mais elementar. Essa aproximação entre o poema e a vida, entre o escrever e o viver, entre o sujeito e sua língua - já que um constrói o outro reciprocamente - tão evidente no poema, também faz parte da linguagem que se torna, a partir do ponto de vista aqui adotado, o locus por excelência da experiência humana. 


\section{Updating the human experience: the poem in question}

\section{Abstract}

The present work aims to discuss the notion of enunciation, by Émile Benveniste, as an actualization of the human experience. In order to do that, the notions of experience and language will be discussed, based on the writings of Giorgio Agamben, Walter Benjamin and Émile Benveniste. At first, it will be considered Agamben's reading of the works of Benjamin and Benveniste, in which the author proposes the experience of language as the origin of history. In a second moment, it will be observed how Benveniste constructs his conception of language as the founder of experience. Finally, we will think about language and the poem, considering the reflections of Henri Meschonnic.

Keywords: Poetic experience. Language. Human experience.

\section{Notas}

1 Espaço// Ainda há espaço/ para um poema// Ainda é o poema/ um espaço// Onde se pode respirar. (Tradução de Irene Aron).

2 "Tomado em si, o pensamento é como uma nebulosa em que nada está necessariamente delimitado. Não existem ideias preestabelecidas, e nada é distinto antes do aparecimento da língua" (SAUSSURE, 2012, p. 158).

3 Em ao menos três textos anteriores, Benveniste utiliza termos como "atualização", "atualizado" e "atualizar-se" para pensar a relação entre língua e discurso: A natureza dos pronomes (1956), Observações sobre a função da linguagem na descoberta freudiana (1956), Categorias de pensamento e categorias de língua (1958).

4 No original em francês: "Le langage re-produit la réalité".
5 Tomamos aqui a noção de poema nos termos de Dessons (2011), para quem o poema não deve ser necessariamente escrito em verso, pois mesmo que o verso tenha sido historicamente a forma do poema, durante muitos séculos, ele não o é mais desde que a ideia de poesia foi alterada no século XVII, quando houve a versificação da prosa, o que resultou no século XIX no poema em prosa. Dessa forma, o poema é considerado como o texto que inventa uma nova forma e um novo sentido, é uma criação.

6 DESSONS, Gérard; NEUMANN, Daiane; OLIVEIRA, Giovane F. Émile Benveniste e a arte de pensar: uma entrevista com Gérard Dessons. ReVEL. (no prelo)

7 MILOSZ, Témoignage de la poésie, p. 124, apud Meschonnic 2006, p. 229.

8 PAULHAN 1966-1970, t. II, p. 267, apud MESCHONNIC 2006, p. 86.

9 "A história é objeto de uma construção cujo lugar não é o tempo homogêneo e vazio, mas um tempo saturado de 'agoras"' (BENJAMIN, 1996, p. 229).

10 Mein Vaterland ist tot/ sie haben es begraben/ im Feuer// Ich lebe/ in meinem Mutterland/Wort Minha pátria está morta/ eles a enterraram/ no fogo// Eu vivo/ em minha mátria/ palavra (Tradução de Irene Aron)

\section{Referências}

AGAMBEN, Giorgio. Infância e História Ensaio sobre a destruição da experiência. In: AGAMBEN, Giorgio. Infância e História. Destruição da experiência e origem da história. Tradução de Henrique Burigo. Belo Horizonte: Editora UFMG, 2008.

AGAMBEN, Giorgio. O fim do poema. Tradução de Sérgio Alcides. In: Revista Cacto, número 1, 2002, p. 142-149.

AUSLÄNDER, Rose. Mátria palavra. Tradução de Irene Aron. In: Revista Pandaemonium Germanicum, número 5, 2001, p. 277-293.

BENJAMIN, Walter. Sobre alguns temas em Baudelaire. In: BENJAMIN, Walter. Charles Baudelaire um lírico no auge no capitalismo. Tradução: José Martins Barbosa, Hemerson Alves Baptista. São Paulo: Brasiliense, 1989. 
BENJAMIN, Walter. O narrador. In: BENJAMIN, Walter. Magia e técnica, arte e política: ensaios sobre literatura e história da cultura. Obras Escolhidas v. 1. Tradução Sergio Paulo Rouanet. São Paulo: Brasiliense, 1996.

BENJAMIN, Walter. Experiência e pobreza. In: BENJAMIN, Walter. Magia e técnica, arte e politica: ensaios sobre literatura e história da cultura. Obras Escolhidas v. 1. Tradução Sergio Paulo Rouanet. São Paulo: Brasiliense, 1996.

BENJAMIN, Walter. Sobre a linguagem em geral e sobre a linguagem do homem. In: BENJAMIN, Walter. Escritos sobre mito e linguagem (1915-1921). São Paulo, Duas Cidades: Editora 34, 2011.

BENJAMIN, Walter. Sobre o programa da filosofia por vir. 1. Ed. Tradução Helano Ribeiro. Rio de Janeiro: 7 Letras, 2019.

BENVENISTE, Émile. Problemas de lingüística geral I. Campinas: Pontes Editora, 2005.

BENVENISTE, Émile. Problemas de lingüística geral II. Campinas: Pontes Editora, 2006.

BENVENISTE, Émile. Baudelaire. France: Limoges, Éditions Lambert-Lucas, 2011.

D'ALEMBERT. Observation sur l'art de traduire en général. In: Euvres de d'Alembert, IV, $1^{\text {a }}$ parte, Belin-Bossange, 1822.

DESSONS, Gérard. Le poème. Paris : Armand Colin, 2011.

MESCHONNIC, Henri. La rime et la vie. France: Éditions Verdier, 1989/ Gallimard, 2006.

SAUSSURE, Ferdinand de. Curso de linguística geral. São Paulo: Cultrix, 2012. 